\begin{tabular}{lcr}
\multicolumn{3}{c}{ ANNALES } \\
UNIVERSITATIS MARIAE CURIE-SKŁODOWSKA & \\
LUBLIN - POLONIA & \\
VOL. LXXIII, 1 & SECTIO AA & 2018 \\
\hline
\end{tabular}

\title{
Strategies in poorly soluble drug delivery systems
}

\author{
Magdalena Szaniawska* and Katarzyna Szymczyk \\ Maria Curie-Sklodowska University, Faculty of Chemistry, \\ Department of Interfacial Phenomena, \\ M. Curie-Sklodowska Sq. 3, 20-031 Lublin, Poland \\ *e-mail: magdalena.szaniawska@poczta.umcs.lublin.pl
}

The form of the active drug administered to patients is important as far as effectiveness of the disease therapy is concerned. From this point of view modifications of medicinal substances are searched for that the obtained compounds have the best physicochemical and pharmacodynamic properties. Pharmaceutical companies allocate significant funds for this type of research. The key property that needs to be improved is the solubility of biologically active substances. This is related to the fact that over $40 \%$ of drugs available on the pharmaceutical market are characterized by low solubility in water.

Thus, the paper describes the most important strategies used in the poorly soluble drug delivery systems, e.g. physical and chemical modifications, formulation based, modification of partition coefficient and lipid systems. The authors discussed various techniques used to enhance solubility of poorly water soluble drugs with their advantages and limitations.

Keywords: solubility, drug delivery systems, bioavailability.

\section{INTRODUCTION}

Interest in the problem of solubility of biologically active compounds is associated with the increasing number of newly synthesized and subjected to treatment substances difficult or 
practically insoluble in water. The Biopharmaceutics Classification System (BCS) is a scientific approach based on the aqueous solubility and intestinal permeability characteristic of the drug substance. BCS is provided by the U.S. Food and Drug Administration. The BCS categorizes drug substances into one of four BCS classes as is presented in Fig. 1 [1-2].

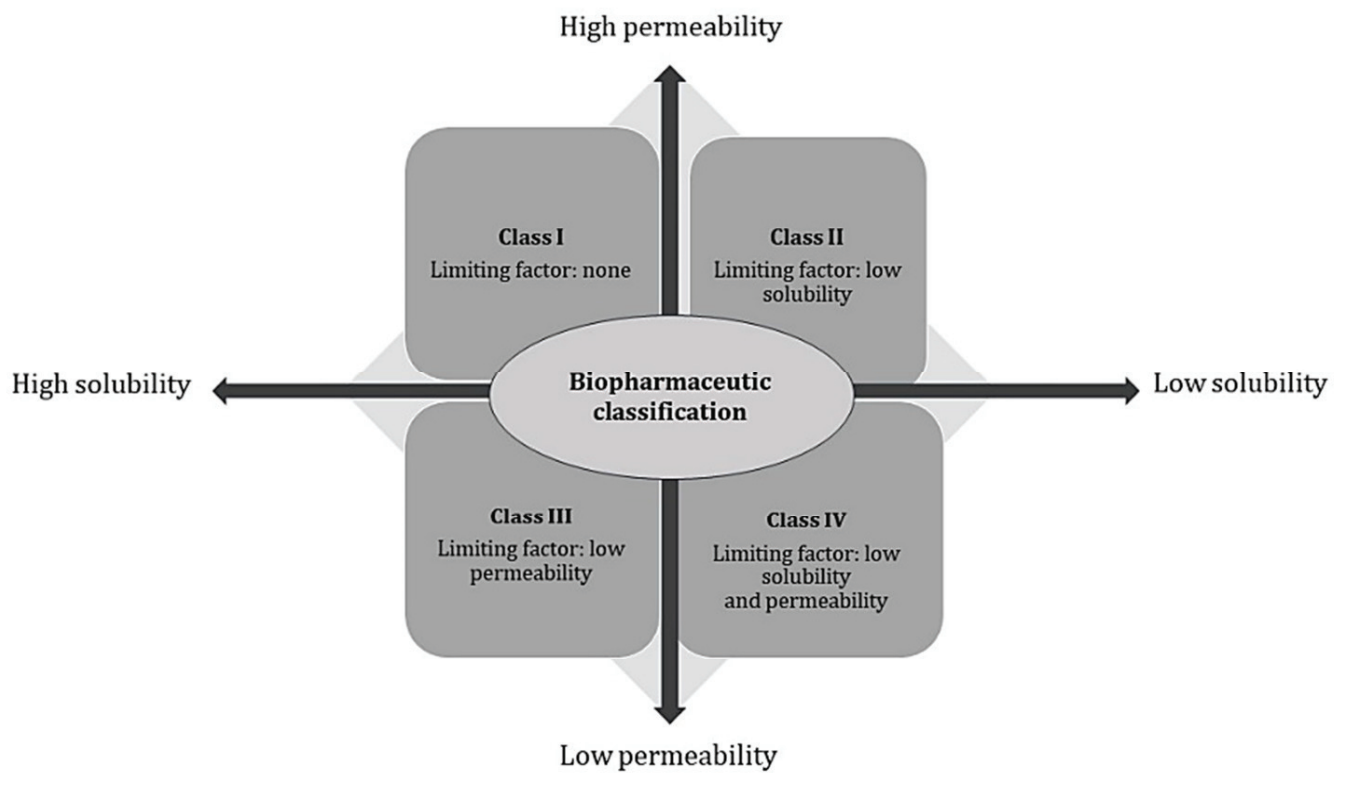

Fig. 1. Biopharmaceutics Classification System.

The most convenient and commonly used route in drug delivery is oral ingestion. It is easy to administer, cost effective and flexible in the design of dosage form [3]. One of major challenge in designing the oral formulations is to improve their bioavailability. This bioavailability depends on several factors including solubility in water, drug permeability, rate of dissolution and metabolism. Also solubility plays a key role in drug delivery, because an important parameter is to achieve a desired concentration of drug necessary for pharmacological response $[4,5]$. It should be noted that poorly water-soluble drugs require high doses in order to reach a therapeutic effect, particularly after the oral administration. Additionally, this drugs with slow drug absorption lead to variable bioavailability and negative effects on the gastrointestinal tract [6].

There are many approaches reported in the literature on enhancement the solubility of poorly water-soluble drugs. These 
techniques can be categorized into four groups as is presented in Fig.2 [7].

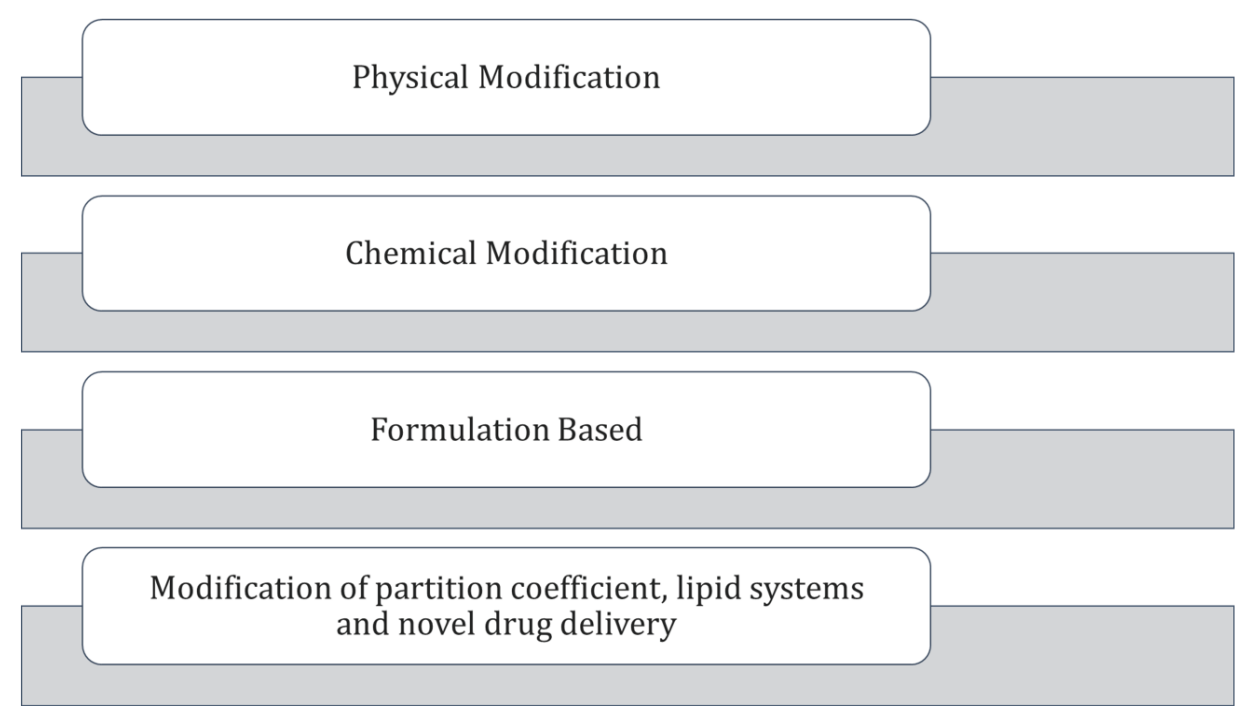

Fig. 2. Techniques used to enhance solubility of poorly-soluble drugs.

\section{PHYSICAL MODIFICATION}

\subsection{Micronization and nanosuspensions}

The solubility of drugs is closely related to the drug particle size and as a particle becomes smaller, the ratio of surface area to volume increases [7]. According to the Noyes-Whitney equation, the rate of dissolution depends on the effective surface area of the drug particles. The larger surface area allows greater interactions between the solute and the solvent which causes an increase in solubility [8]. Conventional methods of particle size reduction, such as spray drying are often incapable of reducing the particle size of nearly insoluble drugs $\left(<0.1 \mathrm{mg} / \mathrm{dm}^{3}\right)$. Nowadays the particle size reduction can be achieved by micronization and nanosuspensions [9].

Micronization results in the formation of particles with the average size diameter $<10 \mu \mathrm{m}$ [10]. The decreasing particle size of drugs improves their rate of dissolution by the increase in the surface area. Micronization proceeds by the milling techniques e.g. jet mill and rotor stator colloid mills. These techniques are not appropriate for drugs having a large dose number [11]. 
Nanosuspensions consist of a poorly water-soluble drug without any matrix material suspended in dispersion. These can be used to increase the solubility of poorly soluble drugs both in water and in lipid media. As a result of the increase solubility, rate of priming of the active compound increases and the maximum plasma level is reached faster. This approach is useful for molecules with poor solubility, poor permeability or both, which is significant a challenge for formulators [12].

\subsection{Co-crystallization}

The other technique used to enhance the solubility of poorly water soluble drugs is co-crystallization. Cocrystal is a crystalline entity formed by two or more different molecular entities, where the intramolecular interactions are weak forces e.g. hydrogen bonding and $\pi-\pi$ stacking [13]. Co-crystals consist of two components: active pharmaceutical ingredient and coformer. Generally, any of the regarded as safe (GRAS)-listed excipients, organic acids (e.g. fumaric acid) and nutraceuticals (e.g. quercetin) can be applied.

The improvement of solubility of drug in cocrystals is achieved by higher solvent affinity and lower lattice energy [14].

\section{CHEMICAL MODIFICATION}

\section{1. $p H$ modification}

It is reported in literature that nearly $70 \%$ of drugs are ionizable and most of them are weakly basic. The dependence of solubility on $\mathrm{pH}$ is exhibited by ionizable drugs; weakly acidic drugs are more soluble at $\mathrm{pH}>\mathrm{pKa}$ and weakly basic drugs are soluble at $\mathrm{pH}<\mathrm{pKa}$ [15]. Taking this into account, $\mathrm{pH}$ control can be used for both oral and parental administration. A poorly soluble drug can be a precipitate upon intravenous administration because blood is strong buffer with $\mathrm{pH}$ around 7.2-7.4. In the stomach the $\mathrm{pH}$ is between 1-2 and in duodenum 5-7.5. Solubilized drugs that increase $\mathrm{pH}$ within a dosage form to a range higher than $\mathrm{pKa}$, affect the increase of solubility of that drug. After $\mathrm{pH}$ adjustment, ionizable excipients are more stable and better soluble. This method is often combined with co-solvents to increase the solubility of the poorly water soluble drugs. The advantages of this method are that it is simple to 
formulate and analyze, it uses small quantitities of compound and is easy and fast to produce $[9,16]$.

The solubility of poorly water soluble compound is increased compared to water alone, so if the drug can permeate through the epithelium orally, the fraction of orally absorbed drug can be increased [5].

\subsection{Salt formation}

Salt formation is the most common and effective method of increasing solubility and dissolution rates of acidic and basic drugs. In 1950s, Nelson and co-workers demonstrated that the rates of dissolution of salt forms of several weakly acidic compounds when the gastrointestinal (GI) tract $\mathrm{pH}$ conditions were much higher that those of free acid forms [17]. They attributed to it a higher dissolution rate of salt higher solubility (relative to the free acid form) in water diffusion layer surrounding the solid. Monkhouse and co-workers [18] reviewed physicochemical and biopharmaceutical advantages of salts over their free acid or base forms.

The salt formation process is relatively simple and consists essentially in the pairing of the parent drug molecule with the appropriate counterion (Fig. 3).

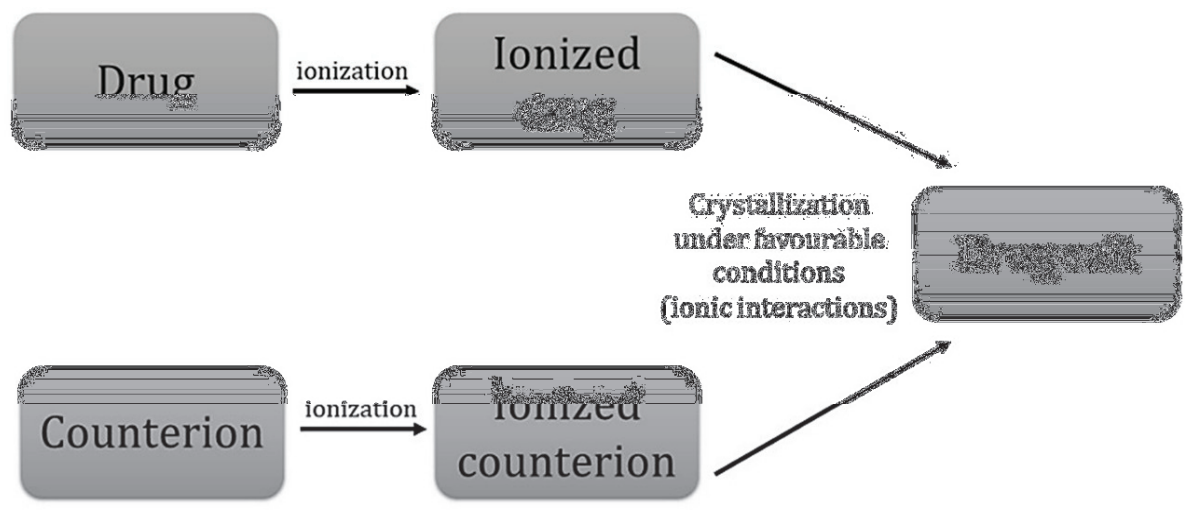

Fig. 3. Diagrammatic illustration of salt formation.

The basic condition is the presence of ionizable functional groups in the drug structure that allow sufficient ionic interactions between the drug and the salt-forming substance. Charged groups in the drug and counterion structure are attracted by ionic intermolecular forces. Under favourable thermodynamic conditions, the salt precipitates in 
a crystallized form $[19,20]$. Typical counterions are used to form salts with acidic drugs, e.g. sodium, potassium and calcium which makes up $90 \%$ of all the counterions. Diethanoloamine is the only organic counterion in the group. About $50 \%$ of basic drugs form salts with inorganic counterion and remaining $50 \%$ with the organic ones [21].

One of the disadvantages of salt formation is that by using a counterion with high molecular weight with a drug with low activity, can indicate that the higher dose is required. If the dose is high, excipients are necessary to improve flow and compressibility. The other problems are the tendency towards hydrate formation and production of polymorphs. There are cases in which salts prepared from strong acids or bases are well soluble in water but they are very hygroscopic. This leads to instability in the formulation [21].

\subsection{Derivatization}

Derivatization is the other method used to enhance solubility of poorly water soluble drugs in which the active ingredient is transformed into a similar chemical structure. This structure is called derivative, which is formed to improve the solubility. It is covalently bound to the inactive part. This provides a desired pharmacological effect [22].

\subsection{Cyclodextrins}

Cyclodextrins (CDs) are widely used as complexing agents for lipophilic and amphiphilic substances and functional excipients that have gained the widespread use and attention due to their ability to solubilize and in some cases stabilize poorly water-soluble drug candidates, enabling both an oral and parenteral administration [23].

Cyclodextrins are cyclic oligosaccharides, which are composed of glucopyranose units bound in the 1,4-configuration to form rings of various diameters. There are three major types of cyclodextrins including $\alpha, \beta$ and $\gamma$, containing 6,7 or 8 glucopyranose units, respectively [24]. The ring has a hydrophilic exterior and a hydrophobic core in which appropriately sized molecules can form non-covalent inclusion complexes (Fig. 4). This process leads to both the increase of aqueous solubility and also chemical stability [25]. Besides solubilization, CDs can be applied for drug protection against light, oxidative and thermal stress, taste masking of drugs and 
reduction of gastrointestinal tract irritation [23]. The most commonly used cyclodextrin in the pharmaceutical formulation is hydroxypropyl- $\beta$-cyclodextrin, derivative of $\beta$-cyclodextrin.

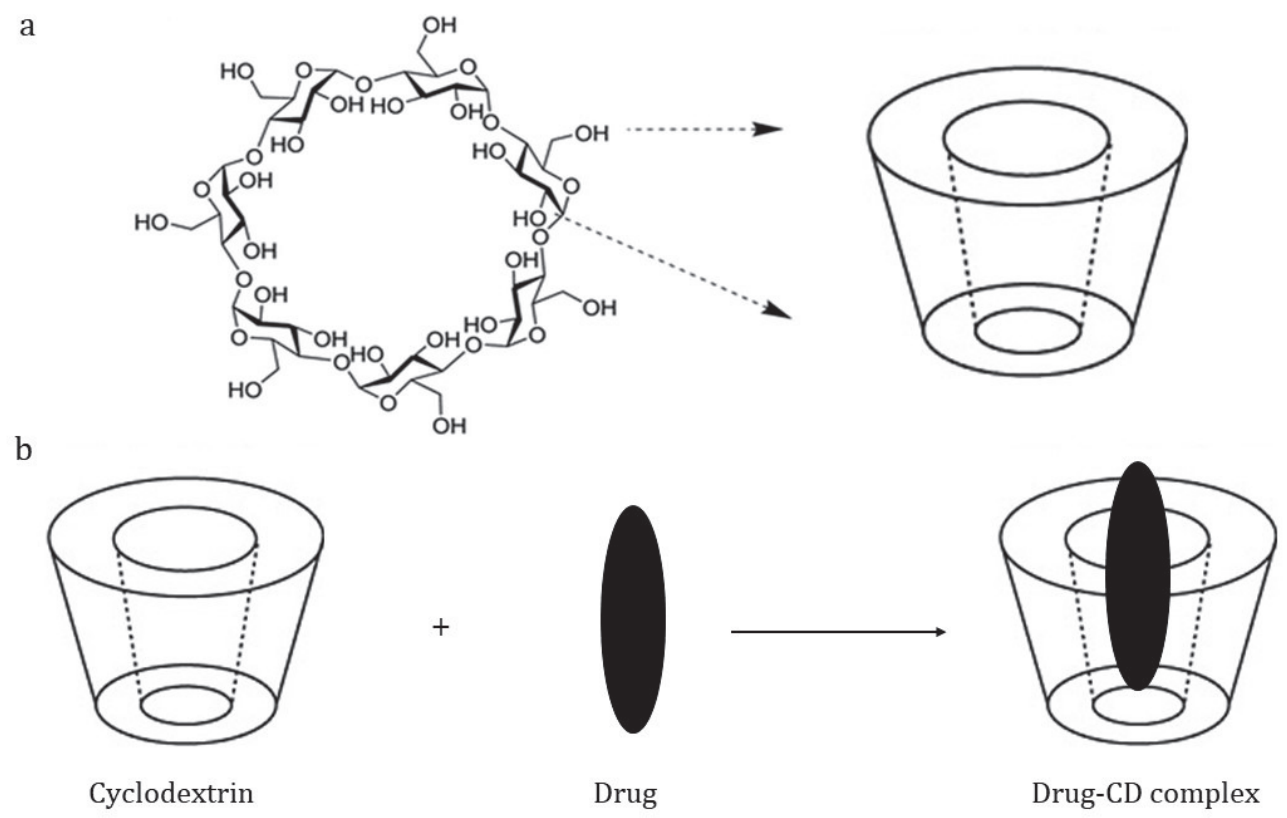

Fig. 4. Schematic illustration of cyclodextrins formation (a) and preparation of drug-cycodextrins complexes (b).

Using complexes solubilization is achieved through specific interactions rather than changes in the bulk solvent properties. The dissociation is very rapid and quantitative. Another advantage is that cyclodextrins are less toxic compared to the other solubilizing agents e.g. surfactants. Despite all the advantages of complexation, there are also disadvantages. A compound has to be able to form complexes with a selected ligand. For the compounds with very poor solubility this technique can be limited [26].

\section{FORMULATION BASED TECHNIQUES}

\subsection{Hydrotropy}

Hydrotropy is a kind of solubilization process, whereby the addition of a large amount of the other solute results in the increase solubility of another solute. The term hydrotropic agent was first 
introduced by Neuberg (1916) to designate anionic organic salts which, at high concentrations, considerably increase the aqueous solubility of poorly soluble solutes [27]. The mechanism of solubility improvement is closely related to complexation with a weak interaction between the hydrotropic agents (e.g. sodium benzoate, sodium acetate and urea) and poorly soluble substance. The most commonly used hydrotropic agents are organic salts. The additives of salts that increase the solubility of given solvent are said to 'salt in' the solute and those that decrease solubility 'salt out' the solute, respectively $[28,29]$.

The hydrotropes are known to self-assemble in solution [30]. The classification of hydrotropes in terms of molecular structure is difficult because many compounds exhibit hydrotropic behaviour. The specific examples can include ethanol, aromatic alcohols, alkaloids, ionic surfactants. They are in a large number because of isomerism. The effective hydrotrope action may be due to the availability of interactive pi $\pi$ orbitals [31].

Because the solvent character is independent of $\mathrm{pH}$, hydrotropy is characterized by high selectivity. It does not require chemical modification of hydrophobic drugs, use of organic solvents or emulsification.

\subsection{Cosolvency}

One of the oldest and widely used technique to enhance solubility of poorly water soluble drugs is cosolvency. This method is used especially for liquid formulation for oral and parenteral administration. Cosolvents are mixtures of water and one (or more) water miscible solvents.

Parenteral formulations may require addition of water or a dilution step with an aqueous media to lower the solvent concentration before administration [32]. Poorly soluble drugs which are hydrophobic or highly crystalline may be suited to this method. This approach can increase the solubility several thousand times compared to the aqueous solubility. Co-solvents may be combined with other techniques e.g. $\mathrm{pH}$ adjustment and solubilization. The most often used cosolvents are polyethylene glycol, dimethylsulfoxide and dimethylacetoamide [33]. 


\subsection{Solid dispersions}

In 1960s Sekiguchi and Obi investigated the generation and dissolution performance of eutectic melts of sulfonamide drug and water-soluble carrier [34]. In this way, the idea of solid dispersions was presented for the first time.

Solid dispersions is a useful technique for increasing the dissolution, absorption and therapeutic effect of drugs in dosage forms. This term refers to solid products which consist at least of two different parts - hydrophilic matrix and a hydrophobic drug. Solid dispersions favour better dissolution of drugs due to the formation of a high-energy amorphous form or increased solubility leading to supersaturation [35]. One of the basic principles of formulating a solid dispersion is to achieve an amorphous state which is considered to be more soluble than the crystalline state. The amorphous state in the solid dispersion system has both its advantages and disadvantages. This can be explained by the fact that in the amorphous state no energy is needed to break up the crystal lattice in the crystalline phase [36]. There are many various methods to obtain solid dispersions (Fig. 5).

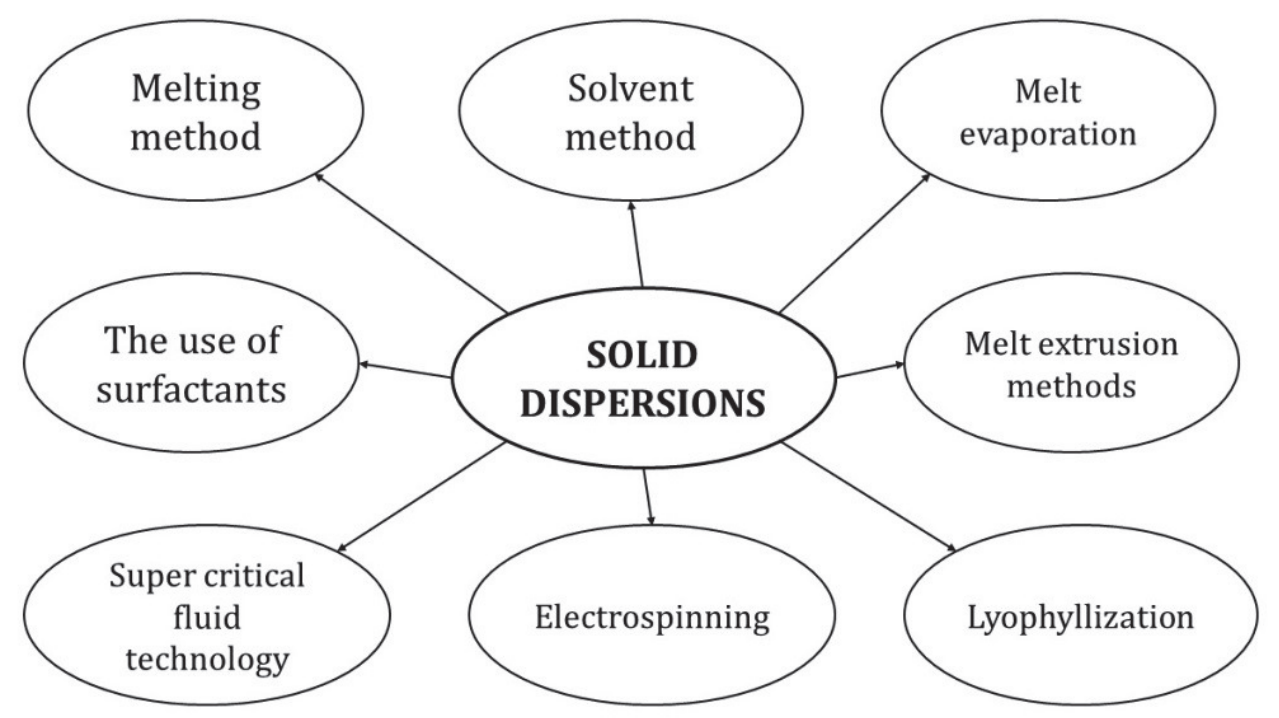

Fig. 5. Methods of solid dispersions preparation.

The choice of carrier affects the dissolution characteristics of the dispersed drug, because the rate of dissolution of one component from the surface has an effect on another one in the multiple component mixture. Therefore, the water-soluble carrier causes 
a faster release of the drug from the matrix. Slightly soluble or an insoluble carrier leads to slower drug release. If the active drug is a secondary component faster release of the drug can be achieved in the dispersion from the matrix [37].

\section{MODIFICATION OF PARTITION COEFFICIENT, LIPID SYSTEMS AND NOVEL DRUG DELIVERY}

\subsection{Microemulsions}

According to the most general definition provided by Danielsson and Lindman in 1981, a microemulsion is defined as 'a system of water, oil and amphiphile which is a single optically isotropic and thermodynamically stable liquid solution' [38]. A microemulsion is an optically clear pre-concentrate, which consist of oil, surfactant and water, frequently in combination with a cosurfactant. This is a thermodynamically stable system with a droplet size in the range of 20-200 $\mathrm{nm}[39,40]$.

Microemulsions are dynamic systems in which the interface is continuously and spontaneously fluctuating. Structurally, they are divided into oil-in-water (o/w), water in-oil (w/o) and bicontinuous microemulsions. In the $\mathrm{w} / \mathrm{o}$ microemulsion, water droplets are dispersed in the continuous oil phase while an o/w microemulsion is formed when oil droplets are dispersed in the continuous aqueous phase. In the systems where the amounts of water and oil are similar, a bicontinuous microemulsion may be formed.

In all three types of microemulsions, the interface is stabilized by an appropriate combination of surfactants and/or co-surfactants. The mixture of oil, water and surfactants is able to form a wide variety of structures and phases depending upon the proportions of the components [41].

In comparison to the conventional emulsion the advantage of microemulsions is that the former produces a stable homogeneous system, which can be prepared over a wide range of surfactant concentrations and oil to water ratios. Surfactants (and mixtures) and co-surfactants play a major role in drugs solubility improvements. 


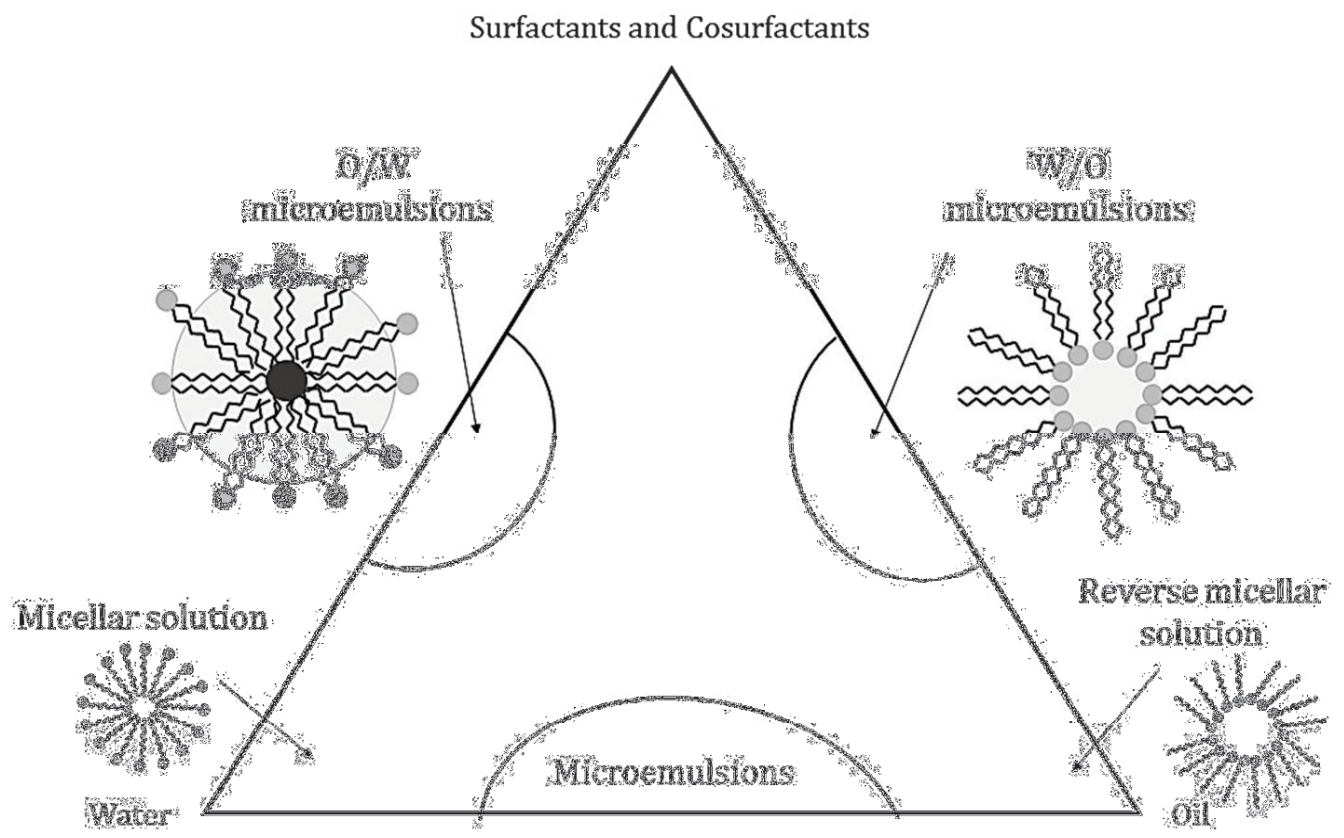

Fig. 6. Phase diagram for microemulsions.

An anhydrous system of microemulsions is a self-microemulsifying drug delivery system (SMEDDS). It has the ability to form the O/W microemulsion when dispersed in the aqueous phase under gentle agitation, which comes from stomach and intestinal motility. The surfactant can be nonionic (polyoxyethylene Brij or sugar esters like Span surfactants), cationic (alkiltrimethylammonium bromide) or anionic (like sodium dodecyl sulfate). It can be found also in combinations of ionic and nonionic surfactants [42-44].

In contrast to microemulsions, SMEDDS do not contain water. Hence, this formulations have improved physical and chemical stability on long-term storage [45]. Additionally, SMEDDS formulations are in capsule or tablet dosage forms, thus occupying a smaller volume [46]. It can be also easily manufactured on a large scale and requires simple and economical manufacturing facilities [47].

\subsection{Micellar solubilization}

The micellar solubilization of poorly soluble drugs by surfactants is an extensively studied topic. Due to their unique structure surfactants can lower the surface tension and enhance the dissolution of hydrophobic drugs in the aqueous solution. When the concentration of a surfactant exceeds the critical micelle 
concentration (CMC), micelle formation occurs. This process is called micellization. With regard to the effect of the drug structure, crystalline solids generally exhibit lower solubility in micelles than liquids with a similar structure. For polar drugs, depth of penetration into a micelle depends on the drug structure. The less polar the drug and if the chain length is longer, the smaller its degree of solubilization $[48,49]$. Surfactants are also used as a stabilizers for drug suspensions.

Commonly used solubilizers include nonionic surfactants, like polysorbates, polyoxyethylated castor oil and mono- and di-fatty acid esters with low molecular weight polyethylene glycols [50]. There can be distinguish two main groups of micelles - mixed and polymeric micelles.

Mixed micelles have a hydrophobic core. Mixed micelles are also called swollen micelles. Mixed micelles is a convenient drug delivery system because it is thermodynamically stable, nano-sized vehicle of typical sizes 5-60 $\mathrm{nm}$ [51].

Polymeric micelles form amphiphilic copolymers spontaneously in an aqueous environment when the critical micelle concentration (CMC) is reached. The differences between the solubility of hydrophilicity and hydrophobic blocks of amphiphilic copolymer in the water solution promote creation of characteristic and unique polymeric micelles with the core-shell architecture. The polymeric micelle diameters range from a few tens to several hundred nanometers [52].

\subsection{Liposomes}

Another technique used to improve the solubility of poorly water soluble drugs is the use of liposomes. Liposomes were first described by the British haematologists in 1961 in the Babraham Institute, in Cambridge. Owing to the unique bilayer-structure properties liposomes are used as carriers for both lipophilic and water-soluble molecules whereas the hydrophilic substances are encapsulated in the interior aqueous compartments [53].

Liposomes are colloidal carriers of size diameter range 0.01 $5.0 \mu \mathrm{m}$ [54]. The basic form of liposome is created by phospholipids. The hydrophilic part is usually phosphoric acid bound to the water soluble molecule whereas the hydrophobic part consists of two fatty acid chains with 10-24 carbon atoms [55]. When phospholipids are 
dispersed in the aqueous medium, they form lamellae. Liposomes can carry the drug in three potential compartments; water-soluble drugs in the central core, lipid-soluble drugs in the membrane, peptide and small proteins at the lipid-water interface [56].

Table.1. Advantages and limitations of some techniques used to enhance the solubility of poorly water soluble drugs.

\begin{tabular}{|c|c|c|}
\hline Strategy & Advantages & Limitations \\
\hline Cosolvency & $\begin{array}{l}\text { - simple and rapid to } \\
\text { formulate; }\end{array}$ & $\begin{array}{l}\text { - toxicity of solvents; } \\
\text { - uncontrolled precipitation } \\
\text { upon dilution; } \\
\text { - worse chemical stability than } \\
\text { in crystalline form; }\end{array}$ \\
\hline Solid dispersions & $\begin{array}{l}\text { - transfer liquid into solid; } \\
\text { - physical stability; }\end{array}$ & $\begin{array}{l}\text { - decomposition or } \\
\text { evaporation during process; }\end{array}$ \\
\hline Microemulsions & $\begin{array}{l}\text { - pre-concentrates are } \\
\text { relatively easy to } \\
\text { manufacture; }\end{array}$ & $\begin{array}{l}\text { - precipitation tendency of the } \\
\text { drug on dilution; } \\
\text { - formulations containing } \\
\text { several components become } \\
\text { more challenging to validate; }\end{array}$ \\
\hline $\begin{array}{c}\text { Micellar } \\
\text { solubilization }\end{array}$ & $\begin{array}{l}\text { - reduced toxicity; } \\
\text { - enhanced permeability; } \\
\text { - longer residence time in the } \\
\text { system; }\end{array}$ & $\begin{array}{l}\text { - high concentration of sur- } \\
\text { factant making this method } \\
\text { unsuitable to IV class BCS; } \\
\text { - recipitation can occur; }\end{array}$ \\
\hline Micronization & $\begin{array}{l}\text { - comparatively simple } \\
\text { process; } \\
\text { - improve rate of absorption } \\
\text { and dissolution rate; }\end{array}$ & - possibility of agglomeration; \\
\hline Co-crystallization & $\begin{array}{l}\text { - good control of chemical } \\
\text { purity; } \\
\text { - stable crystalline form as } \\
\text { compared to amorphous } \\
\text { solid; }\end{array}$ & $\begin{array}{l}\text { - a large number of experi- } \\
\text { ments are necessary to } \\
\text { measure the ternary phase } \\
\text { diagram; }\end{array}$ \\
\hline
\end{tabular}


cont. Table 1.

\begin{tabular}{|c|c|c|}
\hline Strategy & Advantages & Limitations \\
\hline Salt formation & $\begin{array}{l}\text { - effective method to } \\
\text { increasing solubility and } \\
\text { dissolution rates of acidic } \\
\text { and basic drugs; }\end{array}$ & $\begin{array}{l}\text { - high reactivity with } \\
\text { atmospheric carbon dioxide } \\
\text { and water resulting } \\
\text { precipitation; } \\
\text { - not suitable for neutral } \\
\text { compounds; }\end{array}$ \\
\hline Cyclodextrins & $\begin{array}{l}\text { - improvement in chemical } \\
\text { stability of the guest; } \\
\text { - dilution do not result in } \\
\text { supersaturation for very } \\
\text { insoluble drug; }\end{array}$ & $\begin{array}{l}\text { - toxicity of complexing agent; } \\
\text { - structural requirement for } \\
\text { drug; }\end{array}$ \\
\hline Hydrotropy & $\begin{array}{l}\text { - it does not require chemical } \\
\text { modification and } \\
\text { emulsification; } \\
\text { - it only require mixing the } \\
\text { drug with hydrotrope in } \\
\text { water; } \\
\text { - high selectivity; }\end{array}$ & $\begin{array}{l}\text { - there are issues related to } \\
\text { toxicity associated with } \\
\text { excess use of hydrotropic } \\
\text { agents; } \\
\text { - chance of weak interaction } \\
\text { between hydrotropic agent } \\
\text { and drugs; } \\
\text { - complete removal of water } \\
\text { cannot be achieved; }\end{array}$ \\
\hline pH modification & $\begin{array}{l}\text { - simple to formulate and } \\
\text { analyse; } \\
\text { - simple to produce; } \\
\text { - use a small quantitives of } \\
\text { compound; }\end{array}$ & - risk for the precipitation; \\
\hline
\end{tabular}

\section{CONCLUSIONS}

Solubility of drug is the most important factor that controls the formulation of the drug as well as its therapeutic efficacy. The above mentioned techniques can be used alone or in combination to enhance their solubility. It should be remembered that selection of 
a method for solubility improvement depends on many factors, e.g. chemical structure, melting point, physical nature, kinetic behaviour and so on.

\section{REFERENCES}

[1] H. Lennernäs, B. Abrahamsson, Journal of Pharmacy and Pharmacology, 57, 273-285, (2015).

[2] K.T. Savjani, A.K. Gajjar, J.K.Savjani, International Scholarly Research Network, 195727, (2012).

[3] S.R.K. Yellela, Journal of Bioequivalence\&Bioavailability, 2, 28-36, 2010.

[4] K.H. Edward, D. Li, in: Drug Like Properties: Concept, Structure, Design and Methods, from ADME to Toxicity Optimization, Elsevier, p. 56., 2008.

[5] V.R. Vemula, V. Lagishetty, S. Lingala, International Journal of Pharmaceutical Sciences Review and Research, 5, 41-51, (2010).

[6] D. Sharma, M. Soni, S. Kumar, G.D. Cupta, Research Journal of Pharmacy and Technology, 2, 220-224, (2009).

[7] M.R. Baig, A. Shahiwala, S.A. Khan, Advancements in Bioequivalence\&Bioavailability, 1, 1-4, (2018).

[8] D. Brahmankar, S.B. Jaiswal, in: Biopharmaceutics and Pharmacokinetics - A treaties, New Delhi, Vallabh Prakashan, 1995.

[9] A.P. Gowardhane, N.V.Kadam, S. Dutta, American Journal of Drug Discovery and Development, 4, 134-152, (2014).

[10] G. Nykamp, U. Carstensen, B.W. Muller, International Journal of Pharmaceutics, 242, 79-86, (2002).

[11] N. Bladgen, M. de Matas, P.T. Gavan, P. York, Advanced Drug Delivery Reviews, 59, 617-630, (2007).

[12] V.R. Patel, Y.K. Agrawal, Journal of Advanced Pharmaceutical Technology\&Research, 2, 81-87, 2011.

[13] T. Patole, A. Deshpande, International Journal of Pharmaceutical Sciences and Research, 5, 3566-3576, (2014).

[14] R. Thakuria, A. Delori, W. Jones M.P. Lipert, L. Roy, N. RodriguezHornedo, International Journal of Pharmaceutics, 435, 101-125, (2013).

[15] A.T. Serajuddin, Advanced Drug Delivery Reviews, 59, 603-616, (2007).

[16] L. Shargil, Yu, in: Applied biopharmaceutics and pharmacokinetics, Appleton-century crofts, 193-203, 1985.

[17] E. Nelson, Journal of American Pharmaceutical Association (Scientific Edition), 47, 297-299, (1958). 
[18] S.M. Berge, L.D. Bighley, D.C. Monkhouse, Journal of Pharmaceutical Sciences, 66, 1-19, (1977).

[19] B.D. Anderson, R.A. Conradi, Journal of Pharmaceutical Sciences, 74, 815-820, (1985).

[20] P. Makary, Pharmaceutical and Biosciences Journal, 2, 1-4, (2014).

[21] [21]

[22] R.K. Parikh, NS. Mansuri, M.C. Gohel, M.M. Soniwala, Indian Drugs, 42, 149-154, (2005).

[23] S. Göktürk, E. Çalıșkan, R. Yeşim Talman, U. Var, The Scientific World Journal, 718791, (2012).

[24] T. Loftsson, M.E. Brewster, Journal of Pharmaceutical Sciences, 85, 1017-1025, (1996).

[25] K. Uekama, F. Hirayama, T. Irie, Chemical Reviews, 98, 2045-2076, (1998).

[26] D.O. Thompson, Critical Reviews in Therapeutical Drug Carrier System, 14, 1-104, (1997).

[27] C. Neuberg, Biochemistry, 76, 107-109, (1916).

[28] A.M. Saleh, N.A. Daabis, Pharmazie, 29, 525-527, (1974).

[29] A.A. Badwana, L.K. Khordaguib, A.M. Saleh, S.A. Khalil, International Journal of Pharmaceutics, 19, 67-74, (1982).

[30] D. Balasubramanian, S.E. Friberg, in: Surface and Colloid Science, Plenum Press, New York, 15, 197-220, 1993.

[31] K. Nidhi, S. Indrajeet, M. Khushboo, K. Gauri, D.J. Sen, International Journal od Drug Development and Research, 3, 26-33, (2011).

[32] S.H. Yalkowsky, J.T. Rubino, Journal of Pharmaceutical Sciences, 90, 416-421, (1985).

[33] J.,T. Rubino, S.H. Yalkowsky, Pharmaceutical Research, 4, 231-236, (1987).

[34] K. Sekiguchi, N. Obi, Chemical and Pharmaceutical Bulletin, 9, 866872, (1961).

[35] I. Durate, M. Temtem, M. Gil, F. Gaspar, India Pharmacy, 30, 4-6, (2011).

[36] S. Sinka, M. Ali, S. Baboota, A. Ahuja, A. Kumar, J. Ali, American Association of Pharmaceutical Scientist, 11, 518-527, (2010).

[37] I. Sridhar, A. Doshi, B. Joshi, V. Wankhede, J. Doshi, Journal of Scientific and Innovative Research, 2, 685-694, (2013).

[38] S.A.A. Talegonkar, F.J. Ahmad, R.K. Khar, S.A. Pathan, Z.I. Khan, Recent Patents on Drug Delivery\&Formulation, 2, 238-257, (2008).

[39] S. Heschkel, A. Goebel, R.H.H. Neubert, Journal of Pharmaceutical Sciences, 97, 603-631, (2008).

[40] A. Spernath, A. Aserin, Advanced in Colloid and Interface Science, 128-130, 47-64, (2006).

[41] L.B. Lopes, Pharmaceutics, 6, 52-77, (2014). 
[42] K. Ogino, M. Abe, in: Surface and Colloid Science, Plenum Press, New York, 85-95, 1993.

[43] B.K. Paul, S.P. Moulik, Journal of Dispersion Science and Technology, 18, 301-304, (1997).

[44] S.N. Tenjarla, Therapeutic Drug Carrier Systems, 16, 461-521, (1999).

[45] E.A. Mahmoud, E.R. Bendas, M.I. Mohamed, AAPS PharmSciTech, 10, 183-192, (2009).

[46] S. Nazzal, M.A. Khan, International Journal of Pharmaceutics, 315, 110-121, (2006).

[47] C. Sander, P. Holm, AAPS PharmSciTech, 10, 1388-1395, (2009).

[48] M.J. Rosen, in: Surfactants and interfacial phenomena, John Wiley\&Sons, New York, 1989.

[49] A.T. Florence, D. Attwood, in: Physicochemical Principles of Pharmacy, The McMillan Press, London, 2003.

[50] C.O. Rangel-Yagui, A. Pessoa, L.C. Tavares, Journal od Pharmacy and Pharmaceutical Sciences, 8, 147-163, (2005).

[51] Y.E. Alaoui, R. Sefrioui, Y. Bensouda, Y. Rahali, Journal of Chemical and Pharmaceutical Research, 7, 39-46, (2014).

[52] W. Xu, P. Ling, T. Zhang, Journal of Drug Delivery, 340315, (2013).

[53] J.S. Dua, A.C. Rana, A.K. Bhandari, International Journal of Pharmaceutical Studies and Research, 3, 14-20, (2012).

[54] S. Kalepu, S. Kumar, S. Bertha, M. Varma, International Journal of Drug Development\&Research, 4, 62-75, (2013).

[55] D. Yadav, K. Sandeep, D. Pandey, R.K. Dutta, Journal of Biotechnology and Biomaterials, 7, 276, (2017).

[56] G. Bozzuto, A. Molinari, International Journal of Nanomedicine, 10, 975-999, (2015). 
